Low-carbon Innovation, Economic Growth and $\mathrm{CO} 2$ Emission: Evidence from a Dynamic Spatial Panel Approach in China

\title{
Caijiang Zhang
}

South China University of Technology School of Economics and Commerce

Yu Zhou ( $\nabla$ eczhouyu@mail.scut.edu.cn )

South China University of Technology School of Economics and Commerce https://orcid.org/00000002-9328-1280

\section{Zhangwen Li}

South China University of Technology School of Economics and Commerce

\section{Research Article}

Keywords: Carbon Emissions, Low-carbon Innovation, Dynamic Spatial Durbin Model, Cooperative Patent Classification

Posted Date: June 16th, 2021

DOl: https://doi.org/10.21203/rs.3.rs-490799/v1

License: (9) This work is licensed under a Creative Commons Attribution 4.0 International License. Read Full License 


\title{
Low-carbon Innovation, Economic Growth and $\mathrm{CO}_{2}$ Emissions: Evidence from a Dynamic Spatial Panel Approach in China
}

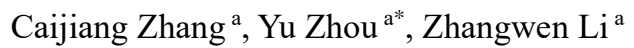 \\ ${ }^{\text {a }}$ School of Economics and Finance, South China University of Technology, Guangzhou, 510006, China
}

\begin{abstract}
Low-carbon technology innovation plays an essential role in carbon emission reduction worldwide. This study investigates how low-carbon innovation affects carbon emissions by the Dynamic Spatial Durbin Model based on the panel data of 30 Chinses provinces from 2007 to 2017. The empirical results show that: Firstly, low-carbon innovation decreases carbon emissions from local and neighbor, the decreasing effects are significant mainly in the short term. Secondly, the results of the heterogeneity test indicate that the weakening effect of low-carbon innovation in central regions is consistent with the national results. The weakening effects are shown in long-term indirect and short-term direct in eastern regions. Thirdly, there is an inverted-U curve between economic development and carbon emissions, confirming the environmental Kuznets curve (EKC) hypothesis. However, the inflection point is insurmountable under the current level of technology in China. Finally, The results also show the "Pollution Paradise" effect.
\end{abstract}

Keywords: Carbon Emissions; Low-carbon Innovation; Dynamic Spatial Durbin Model; Cooperative Patent Classification

Classification codes: O360 R120 Q540 Q550

\section{Introduction}

Since the Industrial Revolution, the concentration of atmospheric greenhouse gas (GHG) produced by fossil fuels and biomass burning has caused global warming, widely recognized, leading to climate change (Atasoy, 2017). As human activity is the source of global warming, taking actions to slow down the carbon emission process becomes a consensus. Hence, several agreements, including the Kyoto Protocol and the Paris Climate Agreement (PCA), were taken out. Furthermore, countries worldwide proposed carbon-neutral goals. As the developing country with the most significant carbon emissions, China proposed the "30-60 target" in 2020, suggesting peaking carbon emissions by 2030 and realizing carbon neutrality by 2060 . To achieve this milestone, China government has been advocating a circular economy and carrying out environmental regulations, such as Carbon Emission Trade (Zhang et al., 2020). Technology innovations, such as knowledge externality, human capital, and Research and Development (R\&D), play an essential role in achieving carbon dioxide neutrality (Arrow, 1962; Lucas, 1988; Romer, 1990, 1986).

Research has been studied the nexus between innovations and carbon emissions (Liu and Liu, 2019; Zhang et al., 2016, 2017). Most studies confirmed the weakening effect of technology innovation on carbon emissions through the Industry-university-research cooperation innovation effect (ICIE) (Song et al., 2020), information and communication effect (Nguyen et al., 2020). Some scholars argued that there exists the non-linear impact of innovation on carbon emissions, implying that innovation decreases environmental pollution, higher innovation exacerbates environmental degradation (Ibrahim and Vo, 2021; Li et al., 2021). However, the impact effect may be positive or negative (Acemoglu et al., 2012), the heterogeneity effect of technological innovation on carbon emissions could be inconsistent under certain conditions. For example, Zhao et al. (2021) argued that only the countries with technological innovations in the top $10 \%$ have inhibitory effects on carbon emissions, while the others promote carbon emissions. Other scholars found the insignificant impacts of technological innovation on carbon emissions in OECD countries, G20 countries, and Japanese (Cheng et al., 2019; Cole et al., 2013; Erdoğan et al., 2020).

Nevertheless, there may exist heterogeneity between general innovation and low-carbon innovation. Low-carbon innovation is the technology innovations for renewable energy supply and efficient end-use energy consumption to reduce

\footnotetext{
* Corresponding Author.

E-mail address: eczhouyu@mail.scut.edu.cn
} 
carbon emissions. The major of the current results support that low-carbon innovation reduces carbon emissions, while general innovation does not (Töbelmann and Wendler, 2020; Wang et al., 2020). Low-carbon innovation impacts carbon emission through innovation input and output (Ding et al., 2021; Khan et al., 2020; Lee and Min, 2015)., and it decreases carbon productivity more than general innovation does (Liu and Zhang, 2021). The result could due to low-carbon innovation offers a more direct measurement. Nevertheless, the impact mechanism of low-carbon innovation on carbon emissions may be heterogeneous in different regions. A threshold effect of low-caron innovation exists regarding income level is proposed. For a high-income level country, the reduction effect is significant, while the weakening effect does not exist in middle-income and low-income countries (Du et al., 2019; Du and Li, 2019).

Environmental Kuznets Curve (EKC) suggested an inverted U-shaped relationship between environmental pollutions and affluence (Bhattarai and Hammig, 2001; Grossman and Krueger, 1995; Stern, 2004). Since then, the validation of the EKC hypothesis starts to merge. Most research finds an inverted-U-shaped EKC relationship between carbon emissions and income (Atasoy, 2017; Cheng et al., 2017; Shahbaz et al., 2020; Yao et al., 2019; You and Lv, 2018). Nevertheless, some suggest that the EKC hypothesis is invalid, which may be an insignificant impact (Erdoğan et al., 2020) or appears a different type of curve (Balin and Akan, 2015; Danesh Miah et al., 2010).

The current studies use different estimate methods to study the relationship between carbon emissions and low-carbon innovations, such as GMM (Töbelmann and Wendler, 2020; Zhang et al., 2017), the non-radial global Malmquist carbon emissions performances index (NGMCPI) (Zhang et al., 2016), second-generation panel integration methodologies (Khan et al., 2020), VAR (Irandoust, 2016), and GS2SLS (Jin, 2019; Radmehr et al., 2021). Nevertheless, a spatial panel model is preferred in analysis when considering the spatial correlations among regions (You and Lv, 2018). Furthermore, most of the current research neglect the dynamic relationship between carbon emissions and low-carbon innovation. Considering that the Dynamic model can eliminate endogeneity and the wildly used in environmental and resource economics (Chen et al., 2017; Feng and Wang, 2020), this paper introduces Dynamic Spatial Durbin Model (DSDM) into our research framework.

The contributions of this paper can be summarized into the following two aspects: First, we use the Dynamic Spatial Durbin Model to discuss the dynamic relationship between carbon emissions and low-carbon innovation. On the one hand, DSDM eliminates the time inertia of carbon emissions, making the estimators of the explanatory variables more accurate. On the other hand, the consideration of spatial correlation makes it possible to measure the spillover effect of explanatory variables. Second, considering the regional gap in China, we carry out a sub-regional estimation to take the heterogeneity into account, clarifying the relationship between low-carbon innovation and carbon emissions in different regions. The results of this paper can help the policymakers in China to understand the relationship between low-carbon innovations and carbon emissions correctly, and the understanding has a positive meaning for carbon peaking and carbon neutral.

The rest of this paper is organized as follows. In the following section, we present the theoretical framework and data used in this paper. Section 3 illustrates the empirical results, discussions and proposes the robustness test and heterogeneity test. Section 4 summarizes and discusses the empirical findings, then concludes with policy implications.

\section{Methodology and Data}

\subsection{STIRPAT model}

IPAT model is a basic framework in environmental pollution research (Ehrlich and Holdren, 1970). The model indicates that environmental pressure is the product of population, affluence, and technology. To overcome the lacking of stochastic impacts in IPAT, Dietz and Rosa (1997) proposed the STIRPAT model based on the IPAT model. Subsequently, the STIRPAT model has been widely utilized in researching the driving forces of environmental pressure, such as haze pollution and carbon dioxide emissions. The model can be expressed as formula (1).

$$
I_{i t}=a P_{i t}^{b} A_{i t}^{c} T_{i t}^{d} e
$$


Where $I, P, A$, and $T$ represent the environmental pressure, population, affluence, and technology, respectively. After taking logarithm to both sides of the equation, the model can express as follows:

$$
\ln I=\ln a+b \ln P+c \ln A+d \ln T+\varepsilon
$$

Where $a$ is a constant term, $b, c$, and $d$ are the parameters to be estimated. $\varepsilon$ is the logarithm of $e$, the resid of the estimation.

\subsection{Spatial panel model}

\subsubsection{Spatial autocorrelation test}

We use spatial autocorrelation to measure carbon emissions' spatial agglomeration in China's provinces (Anselin, 2013). Moran's I is widely used to measure global spatial autocorrelation (Anselin, 1995; Cliff and Ord, 1981; Ord and Getis, 1995). For the linear regression model $Y=X \beta+\varepsilon$, the global Moran's I is presented as (Moran, 1948):

$$
I=\frac{e^{\prime} \boldsymbol{W} e}{e^{\prime} e}
$$

Where $\boldsymbol{W}$ is the spatial weight matrix after row standardization, and $e$ is the residual of the OLS estimation. The value of Moran's $I$ is between -1 to 1 ; when the value of $I$ is higher than zero, there is a positive spatial correlation, showing a "High-High" or "Low-Low" distribution state; the higher the Moran'I index, the stronger the positive autocorrelation. However, a negative value of $I$ reflects a negative spatial correlation, showing a distribution of "HighLow" or "Low-High." When $I=0$, it indicates that there is no spatial correlation.

By decomposing the global Moran's I into the units of each province in China, the local spatial autocorrelation can be obtained, as shown in equation (4), for province i:

$$
\begin{aligned}
I_{i} & =\frac{\left(X_{i}-\bar{X}\right)}{\sum_{i}\left(X_{i}-\bar{X}\right)^{2}} \times \sum_{j} W_{i j}\left(X_{j}-\bar{X}\right) \\
& =Z_{i} \sum_{j} W_{i j} Z_{i j}
\end{aligned}
$$

Among them, the observation value $Z_{i}$ is the weight matrix obtained after the standardized transformation $Z_{i}=$ $\left(X_{i}-\bar{X}\right) / \delta$, and the sum of each row of $Z_{i}$ equals to one and is asymmetric. Use $\mathrm{R}$ software to draw a local Moran's scatter plot of the spatial correlation coefficients of carbon emissions in each province, and analyze the relationship between each province and its neighboring provinces.

\subsubsection{Spatial weight matrix}

According to the previous econometric literature, the spatial weight matrix is used to capture the spillover effects (Corrado and Fingleton, 2012; Lesage and Fischer, 2008). Different methods of making spatial weight matrics are proposed in empirical researches, including binary weight matrix, the inverse distance weight matrix, and the economicbased weight matrix. This paper uses the inverse squared distance matrix for the basic model in section 4 . The matrix is constructed as follows:

$$
w_{i j}=\left\{\begin{array}{l}
\frac{1}{d_{i j}^{2},}, \quad i \neq j \\
0, \quad i=j
\end{array}\right.
$$

Where $w_{i j}$ is the element of the inverse squared distance matrix $W$, which is an NxN row-normalized spatial weight matrix $(\mathrm{N}=30)$, representing the spatial structure of connections among provinces of China. $d_{i j}$ is the geographical distance between the province $i$ and $j$.

\subsubsection{Model specification}

Anselin adjusted the spatial weight matrix and its trace in the LM test formula for cross-sectional data to derive the LM test suitable for the spatial panel. The test statistics are as follows: 


$$
\begin{aligned}
& L M_{E R R}=\frac{\left[e^{\prime}\left(I_{T} \otimes W_{N}\right) e /\left(e^{\prime} e / N T\right)\right]^{2}}{\operatorname{tr} \boldsymbol{Z}} \\
& L M_{L A G}=\frac{\left[e^{\prime}\left(I_{T} \otimes W_{N}\right) y /\left(e^{\prime} e / N T\right)\right]^{2}}{\left[(W \widehat{y})^{\prime} M(W \widehat{y}) / \sigma^{2}\right]+t r \boldsymbol{Z}}
\end{aligned}
$$

Among them, $\boldsymbol{Z}=\left[\left(I_{T} \otimes W_{N}^{2}\right)+\left(I_{T} \otimes W_{N}^{\prime} W_{N}\right)\right]$, $]$ is the residual estimator of the pooled panel, $I_{T}$ represents the identity matrix, and $W \hat{y}=\left(I_{T} \otimes W_{N}\right) X \beta$ is the predicted value after space. $\otimes$ is Kronecker product, $M=I_{N T}-$ $X\left(X^{\prime} X\right)^{-1} X^{\prime}, L M_{E R R}, L M_{L A G}$ both obey the $\chi^{2}$ distribution with 1 degree of freedom.

\subsubsection{Dynamic Spatial Durbin Model}

The traditional panel model can not explain the spatial autocorrelation of carbon emissions and the effects of technology innovation spillover from neighbors(Guo et al., 2019; Liu and Liu, 2019). To solve the previous problem, the Dynamic Spatial Durbin Model is proposed, and it is widely used to describe the relationship between economic growth and convergence between countries or regions. Therefore, this paper establishes the following spatial panel model to examine the influencing factors and spatial spillover effects of low-carbon innovation on carbon emissions in 30 provinces of China. Therefore, the basic model is presented as follows:

$$
\begin{gathered}
\log C E_{t}=\tau \log C E_{t-1}+\eta \boldsymbol{W} \log C E_{t}+\boldsymbol{X}_{t} \boldsymbol{\beta}_{1}+\boldsymbol{W} \boldsymbol{X}_{t} \boldsymbol{\beta}_{2}+v_{t} \\
v_{t}=\rho v_{t-1}+\lambda \boldsymbol{W} v_{t}+\mu+\xi_{t} \iota_{N}+\varepsilon_{t} \\
\mu=\kappa W \mu+\zeta
\end{gathered}
$$

Where

$$
\boldsymbol{X}_{t}=\left[P A T_{t}, G D P_{t}, G D P_{t}^{2}, P D_{t}, I N D_{t}, E I_{t}, F D I_{t}, E S_{t}\right]^{\prime}
$$

Among them, $\log C E_{t}$ is the $1 \times 30$ explanatory variable matrix in period $t, \boldsymbol{X}_{t}$ is a $30 \times 8$ exogenous explanatory variable matrix. The parameters $\tau, \eta$ represent the corresponding parameters of the time lag effect $\log C E_{t-1}$ and the spatial lag effect $\boldsymbol{W} \log C E_{t}$ of the explained variable respectively, $\rho$ is the sequence correlation coefficient, and $\lambda$ is the spatial autocorrelation coefficient of the residual error. $W$ is the spatial weight matrix, and we set it as the inverse square distance spatial weight matrix.

\subsection{Variable selection and data source}

A sample dataset for a panel of 30 provinces from 2000 to 2017 is utilized to investigate the nexus between lowcarbon innovation and carbon emissions (Hongkong, Macaw, Taiwan, and Tibet are not considered due to data unavailability). Notably, the purpose of this study is to address the concern about whether and how low-carbon innovation affects carbon emissions in China; thus, the dependent variable in this paper is carbon emissions, which is estimated by the consumption of fossil fuels derived from China's Energy Statistical Yearbook (2008-2018). The estimation method is proposed by the IPCC (Intergovernmental Panel on Climate Change):

$$
C E=\sum_{j=1}^{17} E C_{j} \times N C V_{j} \times C C_{j} \times O_{j} \times \frac{44}{12}
$$

where $E C_{j}$ is the $j$ th type of fossil fuel consumption, $N C V_{j}$ is the net calorific value of the $j$ th type of fossil fuel, and $C C_{j}$ represents the carbon content of the unit heating value of the $j$ types of energy. $O_{j}$ is the carbon oxidation rate of the jth fossil fuel, and 44/12 is the ratio of the molecular weight of carbon dioxide to the carbon atom.

The other independent variables are illustrated as follows:

(1) Low-carbon innovation (denoted as PAT). As the core independent variable, low-carbon innovation plays an essential part in our study. Green innovation refers to a series of innovation outputs (i.e., improved products, processes, and technologies) for saving energy and reducing environmental pollution (Tariq et al., 2017). CPC (Cooperative Patent Classification) is one kind of patent classification proposed by EPO (European Patent Office) and USPTO (the United States Patent and Trademark Office), in which Y02 indicates patents against climate change. We introduce the number of patent applications under the category CPC-Y02 as the proxy variable of low-caron innovation, sourced from the incoPat database. 
(2) Economic development (denoted as GDP). After Grossman and Krueger (1995) proposed the EKC hypothesis, many scholars have noticed a non-linear relationship between economic development and environmental pressure. Hence, we introduce the level of economic development and its square term, measured by real GDP, and the data are from China's statistical yearbook (2008-2018).

(3) Energy structure (denoted as ES). We use the ratio of coal consumption to total energy consumption to measure energy structure, and the data are from China's energy statistical yearbook (2008-2018).

(4) Industrial structure (denoted as IND). We introduce industrial structure as a control variable, measured by the proportion of the secondary industry's added value to GDP, and the data are derived from China's statistical yearbook (2008-2018).

(5) Foreign Direct Investment (denoted as FDI). We introduce FDI as a control variable, expressed by the ratio of FDI to real GDP. The data are derived from China's statistical yearbook (2008-2018).

(6) Energy intensity (denoted as EI). We introduce energy intensity as a control variable, expressed by energy consumption per unit of GDP, and the data are from China's Energy statistical yearbook (2008-2018).

Population density (denoted as PD). We introduce population density expressed by the permanent residents per square kilometer, and the data are from China's statistical yearbook (2008-2018).

Table 1 shows a summary of descriptive statistics of all the variables, which includes the specific descriptive statistics of all the selected variables. We treat logarithmically to part of variables in this paper to eliminate the impact of heteroscedasticity. Also, we take a moving average to outliers that exceed three times the standard deviations.

Table 1 Descriptive analysis

\begin{tabular}{lcccc}
\hline Variables & Mean & Std. Dev. & Min & Max \\
\hline $\log C E$ & 5.815 & 0.804 & 3.432 & 7.581 \\
$\log P A T$ & 7.049 & 1.381 & 2.485 & 9.890 \\
$\log G D P$ & 2,944 & 2,871 & 62.57 & 17,701 \\
$I N D$ & 0.462 & 0.082 & 0.190 & 0.593 \\
$E I$ & 0.045 & 0.053 & 0.003 & 0.238 \\
$\log F D I$ & 1.491 & 5.551 & 0.002 & 70.86 \\
$E S$ & 0.683 & 0.179 & 0.100 & 0.979 \\
$\log P D$ & 5.441 & 1.275 & 2.033 & 8.249 \\
\hline
\end{tabular}

\section{Empirical results and discussions}

In general, the procedures of the estimations mainly consist of three steps: (1) We analyze the spatial characteristics of carbon emissions across China. (2) This paper verifies the existence of spatial autocorrelation by employing three tests, including LM tests and LR tests. (3) We examine the impact of low-carbon innovation on carbon emissions based on the Dynamic Spatial Durbin model, including the primary and effect decomposition models.

\subsection{Spatial characteristics of carbon emissions}

Figure 1 shows the spatial differentiation characteristics of carbon emissions in 2007, 2011, 2014, and 2017. [W], [C], and [E] in Figure 1 represent the province in the western, central, and eastern regions of China, respectively. Between regions, it shows a slight polarization. The average carbon emissions in eastern regions are higher than in central and western regions.

The high carbon emissions areas are concentrated in specific provinces in all these years. On the one hand, high carbon emissions provinces clustered in three major economic regions, which are relatively developed, including Bohai Rim Economic Circle (Shandong, Hebei, and Liaoning), Yangtze River Delta Economic Circle (Jiangsu), and Pearl River Delta Economic Circle (Guangdong). On the other hand, the carbon emissions in core coal-producing provinces are also maintained at a high level (Shanxi and Inner Mongolia). 
In most provinces, especially in high carbon emissions provinces, there exist a tendency of increasing first and decreasing then on carbon emissions. In these provinces, carbon emissions peak between 2011 and 2014. Simultaneously, the carbon emissions in a small number of provinces maintain a growth trend from 2007 to 2017.

From Figure 1, it can also be concluded that the growth of carbon emission is unbalanced. The increment of carbon emissions in high-emission provinces (such as Shanxi, Shandong, Inner Mongolia) is higher than the increment in lowemission provinces from 2007 to 2014, which also shows the time inertia of carbon emissions.

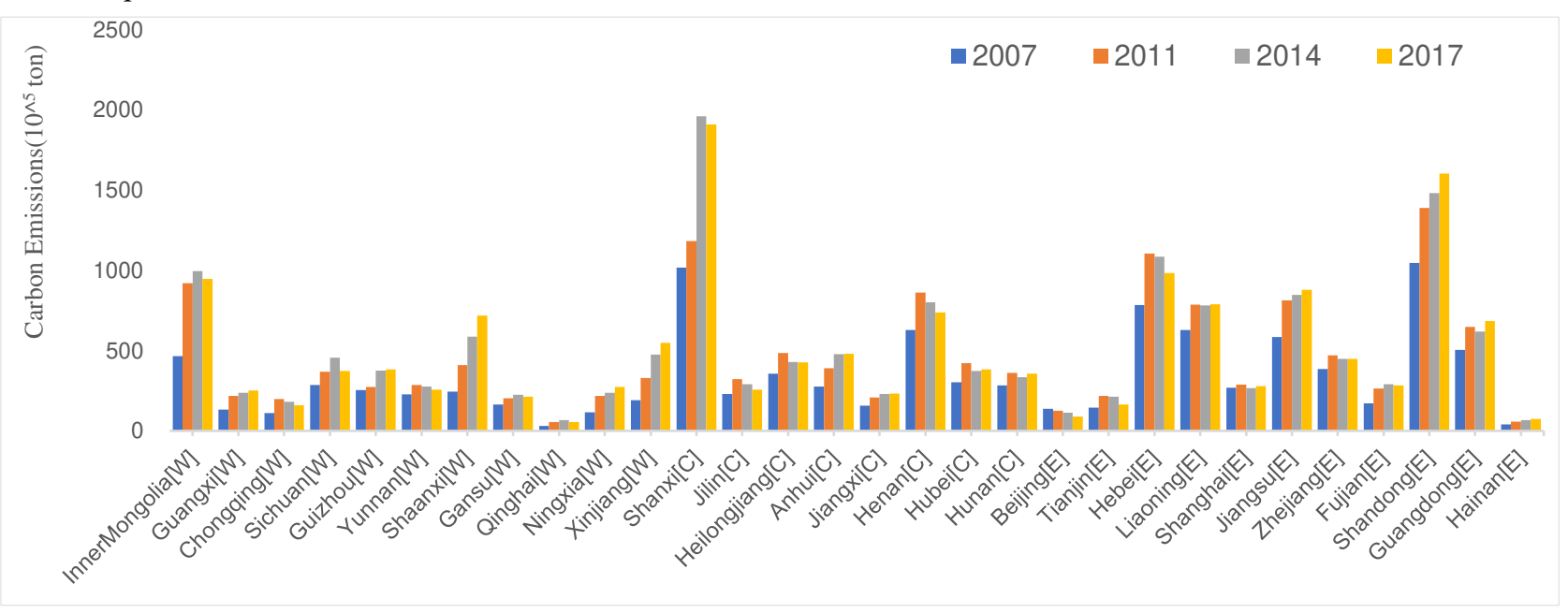

Figure 1 The spatial differentiation of carbon emissions

\subsection{Global and local spatial autocorrelation}

The Moran's I index is used to testing the extent of spatial autocorrelation (Moran, 1948). We use data on carbon emissions in 30 provinces of China to calculate Moran's I index from 2007 to 2017, showed in Table 2. Global Moran's I indexes are consistently positive and are statistically significant at the $1 \%$ level in most years, which shows that there always exists an agglomeration from 2007 to 2017. The index's value fluctuates between 0.176 to 0.207 , indicating the degree of agglomeration has not changed much.

Table 2 Statistical tests of spatial autocorrelation by Global Moran's I

\begin{tabular}{lll}
\hline Year & Moran's I & p-value \\
\hline 2007 & $0.189^{* * *}$ & 0.009 \\
2008 & $0.200^{* * *}$ & 0.006 \\
2009 & $0.207^{* * *}$ & 0.005 \\
2010 & $0.198^{* * *}$ & 0.007 \\
2011 & $0.196^{* * *}$ & 0.007 \\
2012 & $0.184^{* * *}$ & 0.010 \\
2013 & $0.183^{* *}$ & 0.011 \\
2014 & $0.187^{* * *}$ & 0.010 \\
2015 & $0.196^{* * *}$ & 0.007 \\
2016 & $0.176^{* *}$ & 0.013 \\
2017 & $0.178^{* *}$ & 0.012 \\
Average & 0.190 & - \\
\hline Notes: $* * * * * *$ imply the significance at the $10 \%, 5 \%$ and $1 \%$ levels, respectively. &
\end{tabular}

Figure 2 presents the results of Moran scatter plots. Similar to Figure 1, we only report the results in 2007, 2011, 2014, and 2017, which correspond to a), b), c), and d) in Figure 2, respectively. The scatter plots show the carbon emissions and their spatial autocorrelation in each province by the position in the Cartesian coordinate system. The variable represented by the $\mathrm{x}$-axis is the row standardized carbon emissions, and the variable presented by the $\mathrm{y}$-axis is the spatial lag of carbon emissions, which is the weighting of carbon emissions from neighboring regions. The 
characteristics of local spatial autocorrelation summarized as follows: Firstly, Most points are concentrated in the first and third quadrants, and the slope of the trend line is positive, which shows that provinces in China have significant spatial autocorrelations of "H-H" and "L-L," indicating a significant "club" agglomeration phenomenon. The "increasing first, decreasing then" pattern also exists in the Moran Scatter plot. Take Inner Mongolia as an example; the point moves to the right when comparing Figure 2 a) and b), then tunning back left in Figure 2 c) and d).
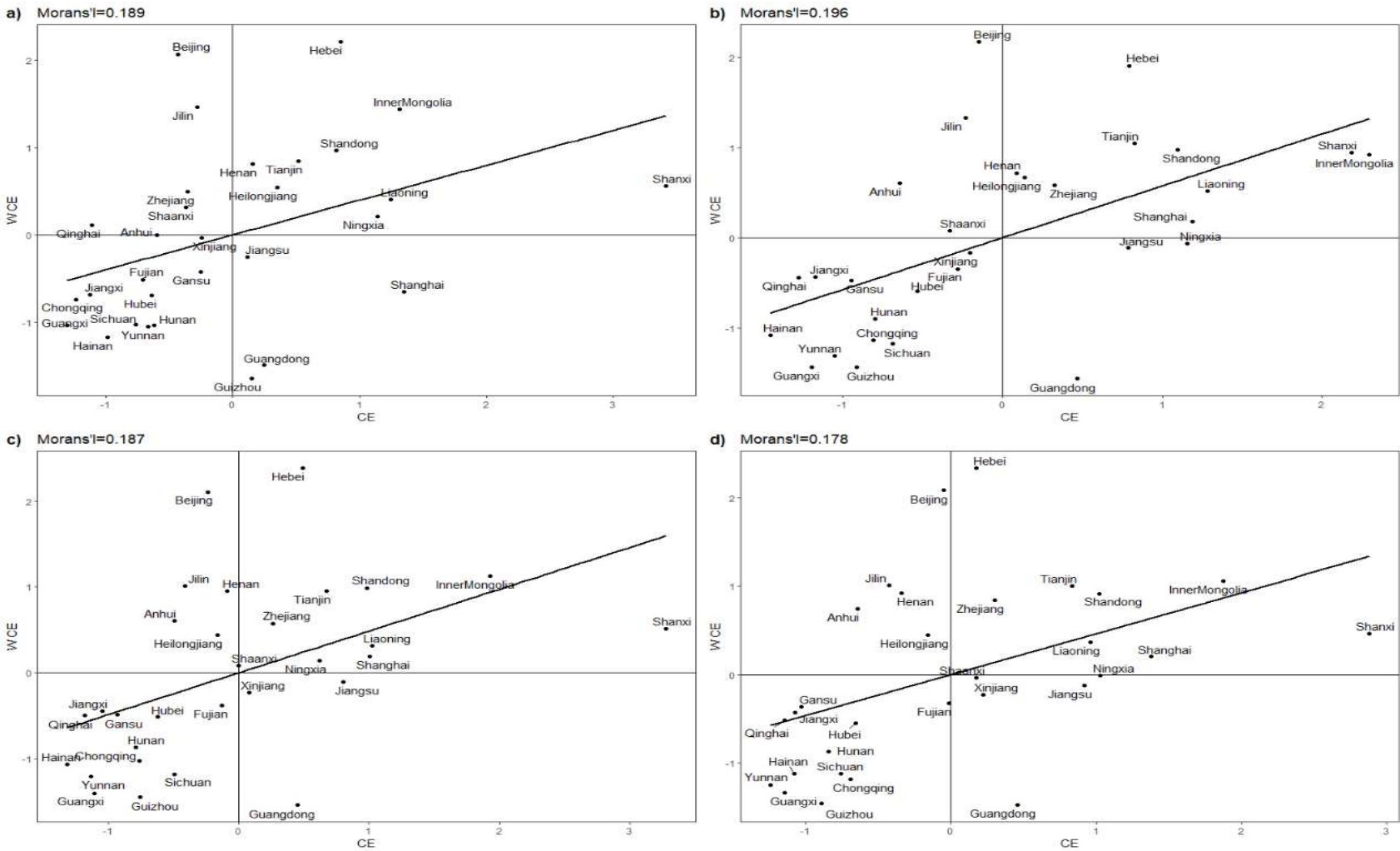

Figure 2 Moran Scatter plot

\subsection{Panel unit root test and cointegration test}

Although this paper's primary purpose is to reveal the spatial relationship between carbon emissions and low-carbon innovation, it is necessary to test whether the model variables are mean stationarity. When all the variables are cointegrated, the error term follows a stationary process (You and Lv, 2018). Hence, it is proper to carry out a spatial panel model.

First, we use panel unit root tests to analyze the existence of time stationarity in variables (Beenstock and Felsenstein, 2015; Chica-Olmo et al., 2020; You and Lv, 2018), including LLC (Levin et al., 2002), IPS (Im et al., 2003), Fisher ADF (Dickey and Fuller, 1979) and Fisher PP (Phillips and Perron, 1988) test. The null hypothesis is that there is a unit root in the panel. Table 3 shows the results of the panel unit root test. We conclude that the variables are nonstationary.

Table 3 Panel unit root test-trend

\begin{tabular}{cccccccccc}
\hline \multirow{2}{*}{ Variables } & \multicolumn{2}{c}{ LLC } & \multicolumn{2}{c}{ IPS } & \multicolumn{2}{c}{ Fisher DF } & \multicolumn{2}{c}{ Fisher PP } \\
\cline { 2 - 9 } & $\mathrm{t}$ & $\mathrm{p}$-value & $\mathrm{z}$ & $\mathrm{p}$-value & $\chi^{2}$ & $\mathrm{p}$-value & $\chi^{2}$ & $\mathrm{p}$-value \\
\hline $\log C E$ & -7.021 & 0.000 & 1.748 & 0.960 & 16.398 & 0 & -2.255 & 0.988 \\
$\log P A T$ & -11.311 & 0.000 & -2.267 & 0.012 & 46.088 & 0 & 3.032 & 0.001 \\
$\log G D P$ & -20.601 & 0.000 & -6.102 & 0.000 & -3.857 & 1.000 & 8.603 & 0.000 \\
$I N D$ & -3.889 & 0.000 & -0.253 & 0.400 & 3.043 & 0.001 & -2.144 & 0.984 \\
$E I$ & -14.553 & 0.000 & -2.860 & 0.002 & 3.490 & 0.000 & 1.966 & 0.025 \\
$E S$ & -2.355 & 0.009 & -7.008 & 0.000 & 2.760 & 0.003 & 19.004 & 0.000 \\
$F D I$ & -17.537 & 0.000 & -4.445 & 0.000 & 3.695 & 0.000 & 1.114 & 0.133 \\
PD & -7.169 & 0.000 & 2.735 & 0.997 & 23.818 & 0 & 2.675 & 0.004 \\
\hline
\end{tabular}


The previous panel unit root test shows the necessity of cointegration tests, which assesses the existence of a longterm cointegration relationship. We use the Pedroni cointegration test to test the existence of cointegration (Pedroni, 2004), which is shown in Table 4. The within-dimensional cointegration test statistics ( $v, \rho$, PP, ADF statistic) and betweendimensional cointegration test statistics ( $\rho, \mathrm{PP}, \mathrm{ADF}$ statistic) indicate that all variables are cointegrated. Therefore, we assume there exists a long-term relationship between the variables.

Table 4 Pedroni cointegration test

\begin{tabular}{|c|c|c|}
\hline & $\chi^{2}$ & $\mathrm{p}$-value \\
\hline \multicolumn{3}{|c|}{ Within-dimension cointegration test } \\
\hline Panel $v$ - statistic & $-9.8706^{* * *}$ & 0.000 \\
\hline Panel $\rho$-statistic & $8.7692^{* * *}$ & 0.000 \\
\hline Panel $P P-$ statistic & $-13.3144^{* * *}$ & 0.000 \\
\hline Panel $A D F$ - statistic & $-9.5163^{* * *}$ & 0.000 \\
\hline \multicolumn{3}{|c|}{ Between-dimension cointegration test } \\
\hline Group $\rho$ - statistic & $10.7224^{* * *}$ & 0.000 \\
\hline Group $P P-$ statistic & $-17.3475^{* * *}$ & 0.000 \\
\hline Group $A D F-$ statistic & $-12.087^{* * *}$ & 0.000 \\
\hline
\end{tabular}

Note: $* * * * *$, and $*$ represent statistical significance at $1 \%, 5 \%$, and $10 \%$ levels. $\mathrm{H} 0$ : no cointegration relationship between the variables

\subsection{Specification of the spatial panel model}

We employ LM tests, the robust LM tests, and LR tests to examine the existence of spatial dependence. The null hypothesis of the LM tests is that there is no spatial lagged term (LM-lag and robust-LM-lag) and spatial error term (LMerror and robust-LM-error).

The results are presented in Table 5. LM-Lag, LM-Error, robust-LM-Lag, and robust-LM-Error values are 604.626, 711.242, 50.548, and 157.164, respectively, which all strongly reject the null hypothesis of the LM test at the $1 \%$ significance level. Thus, the results imply that spatial dependence exists among the data. Therefore, introducing the spatial Durbin model into our analysis is reasonable. The LR-SDM-SAR and LR-SDM-SEM statistics are respectively 94.79 and 96.62, which also refuse to test the null hypothesis; combining the LM test results, this paper finally chooses the Dynamic version of the Spatial Durbin model. The results of the Hausman test are also reported in Table 5. Since the null hypothesis is rejected at the $1 \%$ significant level, the fixed effects model is used to conduct the research.

Table 5 Specifications of the spatial panel model

\begin{tabular}{lcc}
\hline & Statistics & p-value \\
\hline LM lag (Anselin) & 604.626 & 0.000 \\
LM Error (Burridge) & 711.242 & 0.000 \\
LM lag (Robust) & 50.548 & 0.000 \\
LM Error (Robust) & 157.164 & 0.000 \\
LR-SDM-SAR & 94.790 & 0.000 \\
LR-SDM-SEM & 96.620 & 0.000 \\
Hausman test & 47.320 & 0.000 \\
\hline
\end{tabular}

\subsection{Full sample estimation}

Table 6 reports the estimations of the spatial Durbin model and its dynamic version with fixed effects by the biascorrected Quasi-Maximum Likelihood estimation procedure (Lee and Yu, 2010; Yu et al., 2008). Model 1 is the estimation of the Statistic Spatial Durbin Model. Model 2 and 3 are Dynamic Spatial Durbin Models without and with the square of GDP, respectively.

According to Table 6, the dynamic form of SDM is better than the Statistic SDM due to the lower AIC and BIC values and the more significant coefficients in DSDM. Furthermore, the square term of GDP introduced in model 3 is significant, 
proving that model 3 is better than model 2. The Wald test and LR test results reject the null hypothesis in all three models, confirm the rationality of using the Spatial Durbin Model. Therefore, it is reasonable to use the Dynamic Spatial Durbin Model containing the square of GDP (model 3) in our analysis.

The coefficient of $\log C E_{t-1}(0.868)$ is positive and significant, thus indicating the presence of inertia of carbon emissions, which demonstrates a positive impact on carbon emissions of a previous period to the current period. On the other hand, the coefficient of the variable $W \times \log C E$ (0.637) is significantly positive, indicating a positive impact from neighbors' carbon emissions to local carbon emissions.

The variable $\log (P A T)$ coefficient $(\beta=-0.242)$ is negative and significant, suggesting that low-carbon innovation can reduce carbon emission. Moreover, the variable $W \times \log P A T$ is also significantly negative $(\beta=-1.755)$, thus indicating the presence of negative spatial spillover effects on low-carbon innovation for China's provinces, and the spatial distribution of low-carbon innovation is not random.

The coefficients of the variable $\log G D P$ and $\log G D P^{2}$ are positive and negative, respectively; both are significant, indicating the affluence level and carbon emissions have an inverted $U$-shaped relationship, supporting the environmental EKC hypothesis. The sign of PI is positive $(\beta=0.160)$ and significant, indicating the positive impact of population density on carbon emission.

Finally, the coefficients of control variables (IND,EI, $\log F D I$, and $E S$ ) are also significant, indicating that the industry structure, energy intensity, foreign direct investment, and energy structure substantially impact carbon emissions.

Table 6 Estimation results of the Spatial Panel Model

\begin{tabular}{|c|c|c|c|}
\hline & model 1 & model 2 & model 3 \\
\hline & SDM & DSDM & DSDM \\
\hline \multirow[t]{2}{*}{$\log P A T$} & $0.292 * *$ & $-0.161 * * *$ & $-0.242 * * *$ \\
\hline & $(2.410)$ & $(-14.301)$ & $(-21.188)$ \\
\hline \multirow[t]{2}{*}{$\log G D P$} & 0.027 & $0.133 * * *$ & $0.442 * * *$ \\
\hline & $(0.072)$ & (20.167) & $(5.396)$ \\
\hline \multirow[t]{2}{*}{$\log G D P^{2}$} & -0.009 & & $-0.025 * * *$ \\
\hline & $(-0.364)$ & & $(-4.432)$ \\
\hline \multirow[t]{2}{*}{$\log P D$} & 0.091 & $0.098 * * *$ & $0.160 * * *$ \\
\hline & $(0.593)$ & (7.053) & $(10.809)$ \\
\hline \multirow[t]{2}{*}{$I N D$} & $4.151 * * *$ & $2.483 * * *$ & $4.714 * * *$ \\
\hline & $(2.901)$ & (17.668) & (33.690) \\
\hline \multirow[t]{2}{*}{$E I$} & -4.055 & $3.673 * * *$ & $3.560 * * *$ \\
\hline & $(-1.568)$ & $(20.540)$ & $(20.792)$ \\
\hline \multirow[t]{2}{*}{$\log F D I$} & 0.000 & $0.018 * * *$ & $0.015^{* * *}$ \\
\hline & $(0.050)$ & $(24.977)$ & $(28.137)$ \\
\hline \multirow[t]{2}{*}{$E S$} & 0.183 & $0.936^{* * *}$ & $0.950 * * *$ \\
\hline & $(1.252)$ & $(30.671)$ & $(22.644)$ \\
\hline \multirow[t]{2}{*}{$\log C E_{t-1}$} & & $1.000 * * *$ & $0.868 * * *$ \\
\hline & & (42.493) & (38.009) \\
\hline \multirow[t]{2}{*}{$W \times \log C E$} & $0.418^{* * *}$ & $1.453 * * *$ & $0.637 * * *$ \\
\hline & $(3.947)$ & $(34.535)$ & $(16.200)$ \\
\hline \multirow[t]{2}{*}{$W \times \log P A T$} & $-0.639^{*}$ & $-1.770 * * *$ & $-1.755^{* * *}$ \\
\hline & $(-1.906)$ & $(-50.561)$ & $(-50.961)$ \\
\hline \multirow[t]{2}{*}{$W \times \log G D P$} & 0.199 & $0.475 * * *$ & $1.838 * * *$ \\
\hline & $(0.266)$ & $(27.641)$ & (11.091) \\
\hline$W \times \log G D P^{2}$ & -0.039 & & $-0.105 * * *$ \\
\hline
\end{tabular}




\begin{tabular}{|c|c|c|c|}
\hline & $(-0.720)$ & & $(-9.696)$ \\
\hline \multirow[t]{2}{*}{$W \times \log P D$} & 0.362 & $-0.258^{* * *}$ & -0.019 \\
\hline & (1.133) & $(-11.216)$ & $(-0.825)$ \\
\hline \multirow[t]{2}{*}{$W \times I N D$} & $4.086^{* *}$ & $13.442 * * *$ & $18.504 * * *$ \\
\hline & $(2.068)$ & $(68.220)$ & $(102.664)$ \\
\hline \multirow[t]{2}{*}{$W \times E I$} & 0.500 & $53.062 * * *$ & $51.804 * * *$ \\
\hline & $(0.139)$ & $(108.661)$ & (111.080) \\
\hline \multirow[t]{2}{*}{$W \times \log F D I$} & $-0.031 * * *$ & -0.002 & -0.003 \\
\hline & $(-2.894)$ & $(-1.115)$ & $(-1.337)$ \\
\hline \multirow[t]{2}{*}{$W \times E S$} & 0.017 & $3.070^{* * *}$ & $3.246^{* * *}$ \\
\hline & $(0.055)$ & (22.438) & (25.549) \\
\hline Obs. & 300 & 300 & 300 \\
\hline$\theta^{2}$ & 0.268 & 0.125 & 0.207 \\
\hline logLikelihood & -20680 & -20680 & -28510 \\
\hline AIC & 475.2129 & -352.0301 & -351.4069 \\
\hline BIC & 543.5966 & -289.0658 & -281.035 \\
\hline Wald & $35.893 * * *$ & $24084.904 * * *$ & $39447.318^{* * *}$ \\
\hline LR & $33.102 * * *$ & $17590.449 * * *$ & $26362.149^{* * *}$ \\
\hline
\end{tabular}

Note: ${ }^{* * *}, * *$, and * represent statistical significance at $1 \%, 5 \%$, and $10 \%$ levels, respectively; the parentheses' values represent the t-statistics.

It is noteworthy that the estimated coefficients are biased in the Spatial Durbin Model (same as Dynamic Spatial Durbin Model); thus, the model should be decomposed into direct and indirect effects to separate the marginal effects of the explanatory variables (Lesage and Fischer, 2008; LeSage and Pace, 2010), while a short-term and long-term effect in the dynamic model. The direct effects indicate the impact of explanatory variables on carbon emissions, while the indirect effects represent the impact of explanatory variables in neighbor on carbon emissions; the total effects is the summary of direct and indirect effects. For the Dynamic Spatial Durbin Model, Short-term Direct Effects (SDE), Short-term Indirect Effects (SIE); Long-term Direct Effects (LDE), and Long-term Indirect Effects (LIE) can be expressed as:

$$
\begin{gathered}
S D E=\left[(I-\rho W)^{-1}\left(\beta_{1 k} I_{N}+\beta_{2 k} W\right)\right]^{\bar{d}} \\
S I E=\left[(I-\rho W)^{-1}\left(\beta_{1 k} I_{N}+\beta_{2 k} W\right)\right]^{\overline{r s u m}} \\
L D E=\left[((1-\tau) I-(\delta+\eta) W)^{-1}\left(\beta_{1 k} I_{N}+\beta_{2 k} W\right)\right]^{\bar{d}} \\
L I E=\left\{[(1-\tau) I-(\delta+\eta) W]^{-1}\left(\beta_{1 k} I_{N}+\beta_{2 k} W\right)\right\}^{\overline{r s u m}}
\end{gathered}
$$

where $\bar{?}$ denotes the mean diagonal element of the spatial weight matrix, ] denotes an identify matrix, and $\overline{r s u m}$ denotes the operator that calculates the mean row sum of the non-diagonal element. (In our situation, $\eta=0$.)

The direct, indirect, and total effects in the short-term and long-term are reported in Table 7. Regarding our critical explanatory variable, the short-term direct effect of low-carbon innovation is -0.533 , and the short-term indirect effect of it is -4.977. An increase of the low-carbon innovation level in all neighboring provinces and local regions decreases carbon emissions in the local regions, leading to a more significant carbon reduction effect together. The existence of low-carbon innovation reduces regional carbon emissions, and the spillover effect is even higher than the direct effect, leading to the "free-rider" phenomenon. Although it benefits from innovation activity, provinces are motivated to apply the low-carbon innovations spillover from neighbors. It can be interpreted that a single economy unit can not internalize the externalities of environmental pollutants (Danesh Miah et al., 2010).

From Table 7, it can also be concluded that the total effect of low-carbon innovation is significantly positive (3.993) in the long term, which is lower than the absolute value of the total effect in the short term.

The short-term direct effect of GDP is positive (0.796), while the short-term indirect effect negative (-0.045) supports the EKC hypothesis. Similar results appear in the short-term effects, revealing an inverted-U relationship between economic growth and carbon emissions. 
For our other explanatory variables $(P D, I N D, E I, F D I$, and $E S)$, the direct effect, indirect effect, and total effect are all significantly positive in the short term, which indicates that the population density, industry structure, energy intensity, foreign direct investment, and energy structure in local and neighbor all have a positive impact on carbon emissions in local regions. Specifically, the positive coefficients of $\log$ FDI shows the hypothesis of "pollution paradise." Table 7 Direct, indirect, and total effect in short-term and long-term.

\begin{tabular}{|c|c|c|c|c|c|c|}
\hline \multirow[t]{2}{*}{ Variables } & \multicolumn{3}{|l|}{ Short-term } & \multicolumn{3}{|l|}{ Long-term } \\
\hline & Direct effect & Indirect effect & Total effect & Direct effect & Indirect effect & Total effect \\
\hline \multirow[t]{2}{*}{$\log P A T$} & $-0.553 * * *$ & $-4.977 * * *$ & $-5.530 * * *$ & 3.692 & 0.302 & $3.993 * * *$ \\
\hline & $(-16.468)$ & $(-7.968)$ & $(-8.411)$ & $(0.660)$ & $(0.055)$ & (12.867) \\
\hline \multirow[t]{2}{*}{$\log G D P$} & $0.796 * * *$ & $5.535^{* * *}$ & $6.331 * * *$ & -4.185 & -0.425 & $-4.610 * * *$ \\
\hline & (7.612) & $(8.224)$ & (8.384) & $(-0.538)$ & $(-0.056)$ & $(-6.603)$ \\
\hline \multirow[t]{2}{*}{$\log G D P^{2}$} & $-0.045^{* * *}$ & $-0.315 * * *$ & $-0.361 * * *$ & 0.239 & 0.024 & $0.263 * * *$ \\
\hline & $(-6.484)$ & $(-7.771)$ & $(-7.829)$ & $(0.532)$ & $(0.054)$ & $(6.028)$ \\
\hline \multirow[t]{2}{*}{$\log P D$} & $0.173 * * *$ & $0.213 * *$ & $0.387 * * *$ & -0.187 & -0.093 & $-0.280 * * *$ \\
\hline & $(9.959)$ & $(2.538)$ & $(3.922)$ & $(-0.149)$ & $(-0.075)$ & $(-4.040)$ \\
\hline \multirow[t]{2}{*}{$I N D$} & $8.228 * * *$ & $56.123 * * *$ & $64.351 * * *$ & -41.909 & -4.614 & $-46.523 * * *$ \\
\hline & $(17.393)$ & $(8.286)$ & (8.904) & $(-0.547)$ & $(-0.061)$ & $(-12.050)$ \\
\hline \multirow[t]{2}{*}{$E I$} & $12.387 * * *$ & $141.078 * * *$ & $153.465 * * *$ & -103.829 & -7.006 & $-110.836 * * *$ \\
\hline & (11.788) & $(8.310)$ & (8.518) & $(-0.771)$ & $(-0.053)$ & $(-12.977)$ \\
\hline \multirow[t]{2}{*}{$\log F D I$} & $0.016^{* * *}$ & $0.017 * * *$ & $0.034 * * *$ & -0.016 & -0.009 & $-0.025 * * *$ \\
\hline & $(25.001)$ & (3.983) & $(6.991)$ & $(-0.131)$ & $(-0.073)$ & $(-4.080)$ \\
\hline \multirow[t]{2}{*}{$E S$} & $1.578 * * *$ & $10.059 * * *$ & $11.637 * * *$ & -7.564 & -0.869 & $-8.433 * * *$ \\
\hline & $(15.713)$ & (9.033) & $(9.635)$ & $(-0.518)$ & $(-0.061)$ & $(-9.993)$ \\
\hline
\end{tabular}

Note: $* * *, * *$, and $*$ represent statistical significance at $1 \%, 5 \%$, and $10 \%$ levels, respectively; the parentheses' values represent the $t-$ statistics.

\subsection{Robustness test}

Table 8 shows the Dynamic Spatial Durbin Model estimated by two different spatial weight matrics to confirm the robustness of the previous results. The spatial weighting schemes, including binary spatial weight matrix $\left(W_{2}\right)$ and inverse eco-distance matrix $\left(W_{3}\right)$. The results of the model estimated by different spatial weight matrices are consistent. The effects of low-carbon innovation, population, economic development level, foreign direct investment, industry structure, energy structure, and energy intensity on carbon emissions remain the same.

Table 8 Robustness test: change spatial weight matrix

(1)

Model 4

$\log C E_{t-1}$

$\log P A T$

$\log G D P$

$\log G D P^{2}$

$\log P D$

IND

EI

$\log F D I$

ES

$W \times \log P A T$
$0.907 * * *$

$-0.484 * * *$

$0.824 * * *$

$-0.063^{* * *}$

$0.547 * * *$

$6.701 * * *$

$2.615 * * *$

$0.008 * * *$

$0.433 * * *$

$-2.405^{* * *}$
(2)

Model 5

$0.824 * * *$

$-0.394 * * *$

$0.908 * * *$

$-0.060 * * *$

$0.123 * * *$

$4.454 * * *$

$1.757 * * *$

$0.007 * * *$

$0.302 * * *$

$-1.094^{* * *}$ 


\begin{tabular}{ccc}
\hline$W \times \log G D P$ & $3.702^{* * * *}$ & $3.446^{* * *}$ \\
$W \times \log G D P^{2}$ & $-0.234^{* * *}$ & $-0.226^{* * *}$ \\
$W \times \log P D$ & $0.718^{* * *}$ & $-0.254^{* * *}$ \\
$W \times I N D$ & $20.505^{* * *}$ & $14.842^{* * *}$ \\
$W \times E I$ & $37.346^{* * *}$ & $44.052^{* * *}$ \\
$W \times \log F D I$ & $0.042^{* * *}$ & $-0.030^{* * *}$ \\
$W \times E S$ & $1.745^{* * *}$ & $1.984^{* * *}$ \\
$\operatorname{logLikelihood}$ & -48290 & -86.882 \\
$\operatorname{\theta e}^{2}$ & 0.2288 & 0.1639 \\
\hline
\end{tabular}

Notes: $* * *, * *$, and $*$ represent statistical significance at $1 \%, 5 \%$, and $10 \%$ levels, respectively.

Furthermore, Table 9 shows the effect decomposes results of Dynamic Spatial Durbin Model estimated based on the binary spatial weight matrix. After comparing the result in Table 9 and Table 7, it can be concluded that the low-carbon innovation still promotes carbon mitigation. Only the effect in Table 9 is a litter bit lower. In conclusion, the fundamental conclusions of the previous discussion are robust and reliable.

Table 9 The effect decomposes results of DSDM estimated based on binary spatial weight matrix.

\begin{tabular}{|c|c|c|c|c|c|c|}
\hline \multirow[t]{2}{*}{ Variables } & \multicolumn{3}{|l|}{ Short-term } & \multicolumn{3}{|l|}{ Long-term } \\
\hline & Direct effect & Indirect effect & Total effect & Direct effect & Indirect effect & Total effect \\
\hline \multirow[t]{2}{*}{$\log P A T$} & $-0.355^{* * *}$ & $-1.936 * * *$ & $-2.291 * * *$ & -3.067 & -5.164 & $-8.231 * * *$ \\
\hline & $(-24.856)$ & $(-25.156)$ & $(-26.159)$ & $(-0.012)$ & $(-0.021)$ & $(-8.714)$ \\
\hline \multirow[t]{2}{*}{$\log G D P$} & $0.634 * * *$ & $2.969 * * *$ & $3.603 * * *$ & 5.912 & 6.978 & $12.890^{* * *}$ \\
\hline & $(9.661)$ & $(20.870)$ & (19.021) & $(0.018)$ & $(0.021)$ & $(13.513)$ \\
\hline \multirow[t]{2}{*}{$\log G D P^{2}$} & $-0.051 * * *$ & $-0.186 * * *$ & $-0.237 * * *$ & -0.474 & -0.373 & $-0.846^{* * *}$ \\
\hline & $(-11.044)$ & $(-17.986)$ & $(-17.299)$ & $(-0.030)$ & $(-0.024)$ & $(-13.869)$ \\
\hline \multirow[t]{2}{*}{$\log P D$} & $0.514 * * *$ & $0.488 * * *$ & $1.003 * * *$ & 4.214 & -0.610 & $3.604 * * *$ \\
\hline & $(40.275)$ & (12.584) & (22.067) & $(0.033)$ & $(-0.005)$ & $(8.301)$ \\
\hline \multirow[t]{2}{*}{$I N D$} & $5.630 * * *$ & $15.947 * * *$ & $21.577 * * *$ & 49.469 & 28.050 & $77.519^{* * *}$ \\
\hline & (24.426) & $(29.750)$ & (28.503) & $(0.063)$ & $(0.036)$ & (8.966) \\
\hline \multirow[t]{2}{*}{$E I$} & $0.529 *$ & $31.154 * * *$ & $31.683 * * *$ & 10.878 & 102.949 & $113.827 * * *$ \\
\hline & $(1.730)$ & $(36.682)$ & $(28.845)$ & $(0.002)$ & $(0.016)$ & (8.983) \\
\hline \multirow[t]{2}{*}{$\log F D I$} & $0.006 * * *$ & $0.034 * * *$ & $0.039 * * *$ & 0.041 & 0.100 & $0.141 * * *$ \\
\hline & $(12.485)$ & $(34.204)$ & $(33.135)$ & $(0.009)$ & $(0.021)$ & $(10.240)$ \\
\hline \multirow[t]{2}{*}{ ES } & $0.338 * * *$ & $1.391 * * *$ & $1.729 * * *$ & 3.382 & 2.843 & $6.225 * * *$ \\
\hline & $(7.261)$ & (15.086) & (13.581) & $(0.024)$ & $(0.021)$ & $(6.933)$ \\
\hline
\end{tabular}

Note: $* * * * *$, and $*$ represent statistical significance at $1 \%, 5 \%$, and $10 \%$ levels, respectively; the parentheses' values represent the t-statistics.

\subsection{Heterogeneity test: a regional comparison}

To further investigate whether heterogeneity exists in different regions, we re-estimated model 3 using the sub-samples of three regions in China (Eastern, Central, and Western). The estimated results are presented in Table 10. According to Table 10, the spatial interaction $W \times \log C E$ is significantly positive in all three regions of China, consistent with the previous estimation results (model 3). The value of ? is highest in western provinces (6.368), followed by eastern provinces (4.773) and then central regions (3.862), suggesting spatial interaction is the highest in western regions. However, the exogenous interaction is different in individual regions. The self-reinforcing mechanism of carbon emissions is highest in the eastern region (1.027), followed by the western region's value (0.559), indicating that the current carbon emissions are positively affected by the previous period; however, the value of $\tau$ is negative in the central region, suggesting the inexistence of self-reinforcing mechanism in the central region. 
The short-term and long-term effects of low-carbon innovation in the central region are consistent with the national results (model 3), indicating that the carbon reduction effect of low-carbon innovation is representative in the central region. The low-carbon innovations reduce carbon emissions from local regions and neighbors; furthermore, the shortterm direct effect of low-carbon innovation in the central region $(-7.775)$ is more substantial than the eastern region's effect (-2.349).

However, compared with the national results, the coefficients of low-carbon innovation estimated in three regions show different results. The short-term direct effect of low-carbon innovation is negative in eastern regions, but the negative effect is weaker than in central regions. However, the direct and indirect effects in the short term are insignificant in the western regions.

The long-term direct effects in eastern and western regions are positive and significant at a $1 \%$ level, suggesting that in the long run, the local eco-R\&D is ineffective both in developed provinces (eastern) and undeveloped provinces (western).

Table 10 The estimating results of DSDM by regions.

\begin{tabular}{|c|c|c|c|c|c|c|}
\hline & \multirow{2}{*}{\multicolumn{2}{|c|}{$\begin{array}{l}\text { Eastern } \\
\text { Model } 9\end{array}$}} & \multirow{2}{*}{\multicolumn{2}{|c|}{$\begin{array}{c}\text { Central } \\
\text { Model } 10\end{array}$}} & \multirow{2}{*}{\multicolumn{2}{|c|}{$\begin{array}{l}\text { Western } \\
\text { Model } 11\end{array}$}} \\
\hline & & & & & & \\
\hline & Short-term & Long-term & Short-term & Long-term & Short-term & Long-term \\
\hline \multicolumn{7}{|l|}{ Direct effect } \\
\hline $\log P A T$ & $-2.349 * * *$ & $1.310 * * *$ & $-7.775 * * *$ & $-0.429 * * *$ & 12.017 & $0.939 * * *$ \\
\hline $\log G D P$ & $0.826 * * *$ & $0.296^{* *}$ & $-3.912 * * *$ & $-1.610^{* * *}$ & 9.883 & $-0.372 * * *$ \\
\hline $\log G D P^{2}$ & $-0.100 * * *$ & $-0.017 *$ & $0.241 * * *$ & $0.096 * * *$ & -0.567 & $0.019 * * *$ \\
\hline $\log P D$ & $0.878^{* *}$ & $-2.166^{* * *}$ & $5.707 * * *$ & $0.354 * * *$ & -2.886 & $0.131 * * *$ \\
\hline$I N D$ & $27.961 * * *$ & $-10.627 * * *$ & $-29.498 * * *$ & $17.393 * * *$ & 21.205 & $0.696 * * *$ \\
\hline$E I$ & $34.997 * * *$ & $8.291 * * *$ & $711.248^{* * *}$ & $-27.048 * * *$ & -1092.32 & $-79.125 * * *$ \\
\hline $\log F D I$ & $-0.021 * * *$ & $-0.036 * * *$ & $-3.291 * * *$ & $-0.421 * * *$ & 1.309 & $-0.320 * * *$ \\
\hline$E S$ & $1.072 * * *$ & $-1.745^{* * *}$ & $-1.030 * *$ & $1.223 * * *$ & -5.42 & $0.290 * * *$ \\
\hline \multicolumn{7}{|l|}{ Indirect effect } \\
\hline $\log P A T$ & $0.620^{*}$ & $-3.413 * * *$ & $-1.361 * * *$ & $-4.100 * * *$ & -10.5 & $0.435 * * *$ \\
\hline $\log G D P$ & 0.044 & $0.762 * * *$ & $-4.992 * * *$ & $-2.805^{* * *}$ & -9.62 & $0.610 * * *$ \\
\hline $\log G D P^{2}$ & 0.001 & $-0.103 * * *$ & $0.297 * * *$ & $0.171 * * *$ & 0.549 & $-0.035^{* * *}$ \\
\hline $\log P D$ & $-0.801^{*}$ & $2.259 * * *$ & $1.115^{* * *}$ & $3.028 * * *$ & 2.834 & $-0.178 * * *$ \\
\hline$I N D$ & $-5.675^{*}$ & $37.733 * * *$ & $53.658 * * *$ & $-5.414 * * *$ & -19.322 & $1.009 * * *$ \\
\hline$E I$ & 0.234 & $34.560 * * *$ & $-80.453 * * *$ & $339.809^{* * *}$ & 959.944 & $-40.755^{* * *}$ \\
\hline $\log F D I$ & $-0.011^{*}$ & -0.002 & $-1.314 * * *$ & $-1.863 * * *$ & -1.506 & $0.142 * * *$ \\
\hline$E S$ & $-0.672 *$ & $2.231 * * *$ & $3.779 * * *$ & $0.140 * * *$ & 5.366 & $-0.339 * * *$ \\
\hline$W \times \log C E$ & $4.773 * * *$ & & $3.862 * * *$ & & $6.368 * * *$ & \\
\hline $\log C E_{t-1}$ & $1.027 * * *$ & & $-4.947 * * *$ & & $0.559 * * *$ & \\
\hline
\end{tabular}

Notes: $* * *, * *$, and $*$ represent statistical significance at $1 \%, 5 \%$, and $10 \%$ levels, respectively, the parentheses' values represent the t-statistics.

\section{Conclusion and policy implications}

While previous studies have been examined the relationship between innovation and carbon emissions, the understanding of the dynamic nexus between carbon emissions and low-carbon innovation is not clear. Hence, based on the carbon emissions estimated by seventeen kinds of energy consumption, this paper investigates the nexus between carbon emissions and low-carbon innovation using the Dynamic Spatial Durbin Model based on panel data of 30 provinces from 2007 to 2017.

The results can be concluded as follows: 
Firstly, Moran's I index confirms the existence of the provincial agglomeration of carbon emissions from 2007 to 2017. The agglomeration mainly occurs in major economic regions and coal-producing regions. Carbon emissions present a dynamic spatial trend of first rising then lowering.

Secondly, after estimated the DSDM, we find clear evidence to support the existence of significant and negative spatial interactions of low-carbon innovation and carbon emissions, low-carbon innovation plays a vital role in carbon emissions reduction. The results of effect decomposition show that carbon emissions can be reduced by low-carbon innovation from local and neighbors. After sub-dividing China into three regions in the heterogeneity test, we find that the mechanism of low-carbon innovation on carbon emissions is inconsistent. The weakening effect of low-carbon innovation in central regions is entirely consistent with the national results; the reduction of carbon emissions in eastern regions is mainly affected by local low-carbon innovation in the short run and low-carbon innovation from neighbors in the long run.

Thirdly, the findings of current research confirm the existence of environmental EKC under a dynamic framework. However, the inflection point is insurmountable under the current level of technology. Thus, the application of technology innovation is a critical factor, especially the application of eco-technology. Furthermore, the decoupling between carbon emissions and economic development is urgently needed.

Finally, the evidence also indicates that the "Pollution Paradise" effect on FDI exists from 2007 to 2017 (Copeland and Taylor, 1994). As the direct and indirect effect of FDI is significantly positive, it compresses the space of carbon emissions reduction.

Based on the findings mentioned above and the strong policy demand of China government due to the 30-60 target, we propose policy implications as follows:

Firstly, results show a negative direct and spillover effect of low-carbon innovation on carbon emissions. As the application of technology innovation can accelerate the arrival of the inflection point of the EKC, green financial support and green government subsidies are urgently needed to facilitate low-carbon innovation, in line with Sun et al.(2019). Green financial can ease enterprise innovation financing constraints through green investment funds and green bonds, increase the R\&D input of enterprises, stimulate the transformation of low-carbon innovation achievements, then the carbon emissions in local and neighboring regions will be weakened.

Secondly, due to the regional difference in resource endowments, industry position, and supply chain position, innovation strategies suited to local conditions should be proposed. The proposed policies will maximize resource utilization efficiency.

Finally, to deal with the "Pollution Paradise" effect, the developing pattern of "development first, treatment later" is not an alternative option. The external supervision of the carbon emission of foreign-invested enterprises should be strengthened, such as supervision from management and media.

\section{Credit authorship contribution statement}

Caijiang Zhang: Supervision, Project administration, Funding acquisition. Yu Zhou: Conceptualization, Investigation, Methodology, Software, Formal analysis, Writing - original draft, Visualization. Zhangwen Li: Investigation, Data Curation, Writing - Review \& Editing.

\section{Declaration of Competing Interest}

The authors declare that they have no known competing financial interests or personal relationships that could have appeared to influence the work reported in this paper.

\section{Funding Sources}

This research did not receive any specific grant from funding agencies in the public, commercial, or not-for-profit sectors.

\section{References}


Acemoglu, D., Gancia, G., Zilibotti, F., 2012. Competing engines of growth: Innovation and standardization. Journal of Economic Theory 147, 570601.e3. https://doi.org/10.1016/j.jet.2010.09.001

Anselin, L., 2013. Spatial econometrics: methods and models. Springer Science \& Business Media.

Anselin, L., 1995. Local indicators of spatial association-LISA. Geographical analysis 27, 93-115.

Arrow, K.J., 1962. The Economic Implications of Learning by Doing. The Review of Economic Studies 29, 155-173. https://doi.org/10.2307/2295952

Atasoy, B.S., 2017. Testing the environmental Kuznets curve hypothesis across the U.S.: Evidence from panel mean group estimators. Renewable and Sustainable Energy Reviews 77, 731-747. https://doi.org/10.1016/j.rser.2017.04.050

Balin, B.E., Akan, D.M., 2015. Ekc hypothesis and the effect of innovation: a panel data analysis. Journal of Business Economics and Finance 4, 0-0. https://doi.org/10.17261/Pressacademia.201519952

Beenstock, M., Felsenstein, D., 2015. Estimating spatial spillover in housing construction with nonstationary panel data. Journal of Housing Economics 28, 42-58. https://doi.org/10.1016/j.jhe.2014.10.002

Bhattarai, M., Hammig, M., 2001. Institutions and the Environmental Kuznets Curve for Deforestation: A Crosscountry Analysis for Latin America, Africa and Asia. World Development 29, 995-1010. https://doi.org/10.1016/S0305-750X(01)00019-5

Chen, W.Y., Hu, F.Z.Y., Li, X., Hua, J., 2017. Strategic interaction in municipal governments' provision of public green spaces: A dynamic spatial panel data analysis in transitional China. Cities 71, 1-10. https://doi.org/10.1016/j.cities.2017.07.003

Cheng, C., Ren, X., Wang, Z., 2019. The impact of renewable energy and innovation on carbon emission: An empirical analysis for OECD countries. Energy Procedia, Innovative Solutions for Energy Transitions 158, 3506-3512. https://doi.org/10.1016/j.egypro.2019.01.919

Cheng, Z., Li, L., Liu, J., 2017. The emissions reduction effect and technical progress effect of environmental regulation policy tools. Journal of Cleaner Production 149, 191-205. https://doi.org/10.1016/j.jclepro.2017.02.105

Chica-Olmo, J., Salaheddine, S.H., Moya-Fernández, P., 2020. Spatial relationship between economic growth and renewable energy consumption in 26 European countries. Energy Economics 92, 104962. https://doi.org/10.1016/j.eneco.2020.104962

Cliff, A.D., Ord, J.K., 1981. Spatial processes: models \& applications. Taylor \& Francis.

Cole, M.A., Elliott, R.J.R., Okubo, T., Zhou, Y., 2013. The carbon dioxide emissions of firms: A spatial analysis. Journal of Environmental Economics and Management 65, 290-309. https://doi.org/10.1016/j.jeem.2012.07.002

Copeland, B.R., Taylor, M.S., 1994. North-South Trade and the Environment. The Quarterly Journal of Economics 109 , $755-787$. https://doi.org/10.2307/2118421

Corrado, L., Fingleton, B., 2012. Where Is the Economics in Spatial Econometrics? Journal of Regional Science 52, $210-239$. https://doi.org/10.1111/j.1467-9787.2011.00726.x

Danesh Miah, Md., Farhad Hossain Masum, Md., Koike, M., 2010. Global observation of EKC hypothesis for CO2, SOx and NOx emission: A policy understanding for climate change mitigation in Bangladesh. Energy Policy 38, 4643-4651. https://doi.org/10.1016/j.enpol.2010.04.022

Dickey, D.A., Fuller, W.A., 1979. Distribution of the estimators for autoregressive time series with a unit root. Journal of the American statistical association $74,427-431$.

Dietz, T., Rosa, E.A., 1997. Effects of population and affluence on CO2 emissions. Proceedings of the National Academy of Sciences $94,175-179$.

Ding, Q., Khattak, S.I., Ahmad, M., 2021. Towards sustainable production and consumption: Assessing the impact of energy productivity and ecoinnovation on consumption-based carbon dioxide emissions (CCO2) in G-7 nations. Sustainable Production and Consumption 27, $254-268$. https://doi.org/10.1016/j.spc.2020.11.004

Du, K., Li, J., 2019. Towards a green world: How do green technology innovations affect total-factor carbon productivity. Energy Policy $131,240-250$. https://doi.org/10.1016/j.enpol.2019.04.033

Du, K., Li, P., Yan, Z., 2019. Do green technology innovations contribute to carbon dioxide emission reduction? Empirical evidence from patent data. Technological Forecasting and Social Change 146, 297-303. https://doi.org/10.1016/j.techfore.2019.06.010

Ehrlich, P., Holdren, J., 1970. The people problem. Saturday review 4, 42-43.

Erdoğan, S., Yıldırım, S., Yıldırım, D.Ç., Gedikli, A., 2020. The effects of innovation on sectoral carbon emissions: Evidence from G20 countries. Journal of environmental management 267, 110637.

Feng, Y., Wang, X., 2020. Effects of urban sprawl on haze pollution in China based on dynamic spatial Durbin model during 2003-2016. Journal of Cleaner Production 242, 118368. https://doi.org/10.1016/j.jclepro.2019.118368 
Grossman, G.M., Krueger, A.B., 1995. Economic Growth and the Environment. The Quarterly Journal of Economics 110 , $353-377$. https://doi.org/10.2307/2118443

Guo, Q., Zhou, M., Liu, N., Wang, Y., 2019. Spatial Effects of Environmental Regulation and Green Credits on Green Technology Innovation under Low-Carbon Economy Background Conditions. International Journal of Environmental Research and Public Health 16 , 3027. https://doi.org/10.3390/ijerph16173027

Ibrahim, M., Vo, X.V., 2021. Exploring the relationships among innovation, financial sector development and environmental pollution in selected industrialized countries. Journal of Environmental Management 284, 112057. https://doi.org/10.1016/j.jenvman.2021.112057

Im, K.S., Pesaran, M.H., Shin, Y., 2003. Testing for unit roots in heterogeneous panels. Journal of econometrics 115, 53-74.

Irandoust, M., 2016. The renewable energy-growth nexus with carbon emissions and technological innovation: Evidence from the Nordic countries. Ecological Indicators 69, 118-125.

Jin, J., 2019. The effects of labor market spatial structure and the built environment on commuting behavior: Considering spatial effects and selfselection. Cities 95, 102392. https://doi.org/10.1016/j.cities.2019.102392

Khan, Z., Ali, S., Umar, M., Kirikkaleli, D., Jiao, Z., 2020. Consumption-based carbon emissions and international trade in G7 countries: the role of environmental innovation and renewable energy. Science of the Total Environment 730, 138945.

Lee, K.-H., Min, B., 2015. Green R\&D for eco-innovation and its impact on carbon emissions and firm performance. Journal of Cleaner Production $108,534-542$

Lee, L., Yu, J., 2010. Estimation of spatial autoregressive panel data models with fixed effects. Journal of Econometrics 154, 165-185. https://doi.org/10.1016/j.jeconom.2009.08.001

Lesage, J.P., Fischer, M.M., 2008. Spatial Growth Regressions: Model Specification, Estimation and Interpretation. null 3, 275-304. https://doi.org/10.1080/17421770802353758

LeSage, J.P., Pace, R.K., 2010. Spatial Econometric Models, in: Fischer, M.M., Getis, A. (Eds.), Handbook of Applied Spatial Analysis: Software Tools, Methods and Applications. Springer, Berlin, Heidelberg, pp. 355-376. https://doi.org/10.1007/978-3-642-03647-7_18

Levin, A., Lin, C.-F., Chu, C.-S.J., 2002. Unit root tests in panel data: asymptotic and finite-sample properties. Journal of econometrics $108,1-24$.

Li, L., McMurray, A., Li, X., Gao, Y., Xue, J., 2021. The diminishing marginal effect of R\&D input and carbon emission mitigation. Journal of Cleaner Production 282, 124423. https://doi.org/10.1016/j.jclepro.2020.124423

Liu, F., Liu, C., 2019. Regional disparity, spatial spillover effects of urbanisation and carbon emissions in China. Journal of Cleaner Production 241, 118226. https://doi.org/10.1016/j.jclepro.2019.118226

Liu, X., Zhang, X., 2021. Industrial agglomeration, technological innovation and carbon productivity: Evidence from China. Resources, Conservation and Recycling 166, 105330. https://doi.org/10.1016/j.resconrec.2020.105330

Lucas, R.E., 1988. On the mechanics of economic development. Journal of Monetary Economics 22, 3-42. https://doi.org/10.1016/03043932(88)90168-7

Moran, P.A., 1948. The interpretation of statistical maps. Journal of the Royal Statistical Society: Series B (Methodological) 10, $243-251$.

Nguyen, T.T., Pham, T.A.T., Tram, H.T.X., 2020. Role of information and communication technologies and innovation in driving carbon emissions and economic growth in selected G-20 countries. Journal of environmental management 261, 110162.

Ord, J.K., Getis, A., 1995. Local spatial autocorrelation statistics: distributional issues and an application. Geographical analysis 27, $286-306$.

Pedroni, P., 2004. Panel Cointegration: Asymptotic and Finite Sample Properties of Pooled Time Series Tests with an Application to the PPP Hypothesis. Econometric Theory 20, 597-625

Phillips, P.C., Perron, P., 1988. Testing for a unit root in time series regression. Biometrika 75, 335-346.

Radmehr, R., Henneberry, S.R., Shayanmehr, S., 2021. Renewable Energy Consumption, CO2 Emissions, and Economic Growth Nexus: A Simultaneity Spatial Modeling Analysis of EU Countries. Structural Change and Economic Dynamics 57, 13-27. https://doi.org/10.1016/j.strueco.2021.01.006

Romer, P.M., 1990. Endogenous Technological Change. Journal of Political Economy 98, S71-S102. https://doi.org/10.1086/261725

Romer, P.M., 1986. Increasing Returns and Long-Run Growth. Journal of Political Economy 94, 1002-1037. https://doi.org/10.1086/261420

Shahbaz, M., Raghutla, C., Song, M., Zameer, H., Jiao, Z., 2020. Public-private partnerships investment in energy as new determinant of CO2 emissions: The role of technological innovations in China. Energy Economics 86, 104664. https://doi.org/10.1016/j.eneco.2020.104664

Song, Yanwu, Zhang, J., Song, Yingkang, Fan, X., Zhu, Y., Zhang, C., 2020. Can industry-university-research collaborative innovation efficiency reduce 
carbon emissions? Technological Forecasting and Social Change 157, 120094. https://doi.org/10.1016/j.techfore.2020.120094

Stern, D.I., 2004. The Rise and Fall of the Environmental Kuznets Curve. World Development 32 , $1419-1439$. https://doi.org/10.1016/j.worlddev.2004.03.004

Sun, H., Edziah, B.K., Sun, C., Kporsu, A.K., 2019. Institutional quality, green innovation and energy efficiency. Energy Policy 135 , 111002. https://doi.org/10.1016/j.enpol.2019.111002

Töbelmann, D., Wendler, T., 2020. The impact of environmental innovation on carbon dioxide emissions. Journal of Cleaner Production $244,118787$. https://doi.org/10.1016/j.jclepro.2019.118787

Wang, L., Chang, H.-L., Rizvi, S.K.A., Sari, A., 2020. Are eco-innovation and export diversification mutually exclusive to control carbon emissions in G-7 countries? Journal of Environmental Management 270, 110829. https://doi.org/10.1016/j.jenvman.2020.110829

Yao, S., Zhang, S., Zhang, X., 2019. Renewable energy, carbon emission and economic growth: A revised environmental Kuznets Curve perspective. Journal of Cleaner Production 235, 1338-1352. https://doi.org/10.1016/j.jclepro.2019.07.069

You, W., Lv, Z., 2018. Spillover effects of economic globalization on CO2 emissions: A spatial panel approach. Energy Economics 73, $248-257$. https://doi.org/10.1016/j.eneco.2018.05.016

Yu, J., de Jong, R., Lee, L., 2008. Quasi-maximum likelihood estimators for spatial dynamic panel data with fixed effects when both n and T are large. Journal of Econometrics 146, 118-134. https://doi.org/10.1016/j.jeconom.2008.08.002

Zhang, N., Wang, B., Liu, Z., 2016. Carbon emissions dynamics, efficiency gains, and technological innovation in China's industrial sectors. Energy 99, 10-19.

Zhang, Y.-J., Peng, Y.-L., Ma, C.-Q., Shen, B., 2017. Can environmental innovation facilitate carbon emissions reduction? Evidence from China. Energy Policy 100, 18-28. https://doi.org/10.1016/j.enpol.2016.10.005

Zhang, Y.-J., Shi, W., Jiang, L., 2020. Does China's carbon emissions trading policy improve the technology innovation of relevant enterprises? Business Strategy and the Environment 29, 872-885.

Zhao, J., Shahbaz, M., Dong, X., Dong, K., 2021. How does financial risk affect global CO2 emissions? The role of technological innovation. Technological Forecasting and Social Change 168, 120751. https://oi.org/10.1016/j.techfore.2021.120751 


\section{Supplementary Files}

This is a list of supplementary files associated with this preprint. Click to download.

- GA.docx 